\title{
Design of a Smart Home System Using Bluetooth Protocol
}

\author{
Sandile Zondo \\ Department of Electrical Engineering \\ and Electronic Engineering \\ University of Johannesburg \\ Johannesburg, South Africa \\ Email: 217051125@student.uj.ac.za
}

\author{
Kingsley Ogudo \\ Department of Electrical and \\ Electronic Engineering \\ University of Johannesburg \\ Johannesburg, South Africa \\ Email: kingsleyo@uj.ac.za
}

\author{
Patrice Umenne \\ Department of Electrical and Mining \\ Engineering \\ University of South Africa \\ Johannesburg, South Africa \\ Email: umennpo@unisa.ac.za
}

\begin{abstract}
Home automation is an intelligent, functional as a unit system that facilitates home processes without unnecessarily complicating the user's life. Devices can be connected, which in turn connect and talk through a centralized control unit, which are accessible via mobile phones. These devices include lights, appliances, security systems, alarms and many other sensors and devices. This paper presents the design and implementation of a Bluetooth based smart home automation system which uses a Peripheral interface controller (PIC) microcontroller (16F1937) as the main processer and the appliances are connected to the peripheral ports of the microcontroller via relays. The circuit in the project was designed in Diptrace software. The PCB layout design was completed. The fully functional smart home prototype was built and demonstrated to functional.
\end{abstract}

Keywords-Micro-controller, Home automation, Sensor, Relay, Bluetooth.

\section{INTRODUCTION}

Smart home automation is the practice of using internetenabled devices to remotely and automatically control appliances, in and around your home. You could use your phone to control most of these appliances. Smart homes are gaining popularity day-by-day with some numerous benefits. Industries and researchers are working hard to build sustainable and low cost automatic systems to monitor and control different machines like lights, fans and motors. Smart phones can be used to control devices in a smart home. Systems based on the Bluetooth protocol are faster than most of the other technologies [1]. Bluetooth is very effective for serial data communication where data can be transmitted at speeds of up to $3 \mathrm{mbps}$ at a distance of $10-100 \mathrm{~m}$. Automation systems not only alleviate the wastage of electricity in a house but also reduce human effort in switching on and off home appliances . Home automation is an important application of wireless technologies like Bluetooth. Homes require sophisticated control of different gadgets such as electronic appliances [2]. Home appliances can be integrated to smart phones via Bluetooth as in [3]. Bluetooth works at a frequency range of 2.4 $\mathrm{GHz}$ over a distance of $100 \mathrm{~m}$ with a speed of $1 \mathrm{Mbps}$. This is an efficient solution for controlling the process of home automation. A microcontroller can be used as a device controller for home devices.

The aim of the project is to construct and implement a smart home automation system using bluetooth technology and android smart phone to control home appliances through smart phone application. Facilitate the use of technology for home appliances which will reduce electricity wastage and increase house safety. To implement a reliable and low-cost home automation system that can be used to access electrical appliances at home.

\section{LITERATURE REVIEW}

Information technology can be used in smart homes to control appliances as in [4]. The main objective in the development of smart homes is to be able to control home appliances to make the life of people easier. Researchers are currently improving the technology behind the smart homes in order to make them more easily affordable.

Smart homes can tell you the status of connected devices at home through a user-friendly interface as in [5]. Some of the major communication technologies used in smart homes include Bluetooth, WiMAX, Wireless LAN(Wi-Fi), ZigBee, and GSM for Mobile communication [5]. The research work in [6] gives details to control home appliances via wireless communication between an Arduino (Bluetooth) device and cell phone using the Bluetooth technology.

In a smart home two kinds of communication can be utilized wireless and wired as can be seen in [7]. Wireless normally occurs between the smart phone and the microcontroller and wired between the controller and the devices. A Graphical user interface can also be developed for the phone.

Earlier on smart home automation systems where plagued by high costs as described in [8], but as time passed and the development in technology, devices became smaller in size and smart home automation systems became more cost effective and popular. Smart home protocols that can be used include X10, Zigbee, Lon Talk and CEBus.

Everything seems to matter in the environment; the need for sustainable development is an important factor towards the future of man. The world summit on sustainable development at Johannesburg in 2002 has brought to the attention of people around the world the deteriorating condition of our environment. It is clear that no person in the world can afford to be ignore the problems we have in the environment. Environmental management has captured the attention of healthcare workers. Managing environmental hazards has become very important. Home automation systems can enable home owners to control and monitor home appliances from anywhere, give them control over energy consumption, enable them control cost of utilization and contribute to the improvement of environmental issues. 
Energy efficiency has become a very important part of energy policy in many countries because, energy saved in megawatts contributes to security of supply, sustainable energy prices and environmental protection [9].

The international Energy Agency (IEA) refers to energy efficiency as "first fuel", considering it to be a major energy resource. In 2009 their analysis showed that by 2035 two-thirds of the economic potential of energy savings would be lost if the policy activity is not increased [10].

Bridging this efficiency gap requires owners of commercial and residential properties to take action. The decisions of single family homeowners will collectively have an influence on the energy future.

The proportion between utilization and generation of electricity is a research topic addressed by smart grids. Smart grids [1113] research also deals with energy storage, distribution automation, demand response etc. The intention of smart grids is to make electricity more reliable. Peak load is a term used in energy demand management and refers to a period when electrical consumption is significantly higher than the supply level. Smart home management systems can be used to reduce the electrical consumption and hence the peak load.

Systems that control themselves are becoming more intelligent and independent. Internet of Things (IoT)[14 - 15] can assist to achieve improved connectivity to machines, systems and smart homes. Internet of things can connect to smart homes in order to improve the control of smart homes. Fig. 1 shows the transition from the network, to the internet, to the mobile-internet, to mobile phones and people and finally to the internet of things and smart homes control.

The devices in the smart homes can be computers, household devices, industrial equipment or any other device that you can assign an (Internet Protocol) IP address to. Devices will therefore be able to transfer data over the network. IoT will be able to join digital entities and have a new class of functionality. This is the future of smart homes. Currently smart homes can operate with sensor and electronic devices connected to home areas, but in the future IoT will integrate with devices to achieve home automation systems. Then control of devices in the home will be attainable from everywhere, because these devices can be connected to the internet.

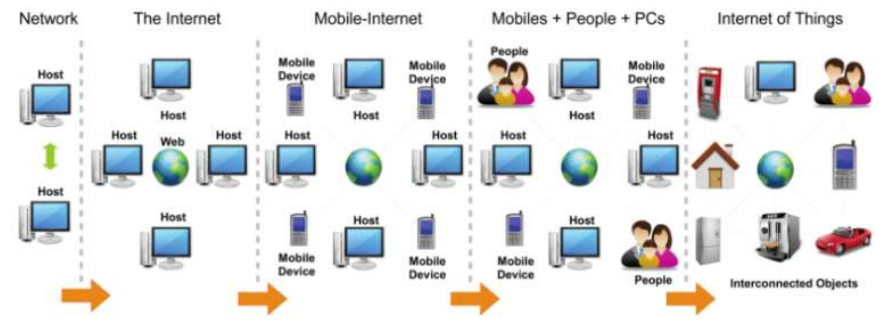

Fig. 1 From Internet of People to Internet of Things [16]

Humans have developed technologies to achieve advancement goals. Improvements in technology have resulted in improvements in social structures. The industrial revolution brought improvements to socio-economic structures. These advances in technology makes it possible to automate work done by humans. The advancement in technology can lead to reduction in jobs done by humans. Human workers could be replaced by automation processes. Although technology may remove some jobs it can also create new ones and in addition to these create wealth in society.

Recently there has been an increase in the use of smart home technology in the United States. The digital revolution has led to a new exciting period in companies dealing with home automation, offering customers improved home technologies. Leading to interconnected, easy-to-use environment called a "smart home". These devices enable customers to be able to monitor smart homes and have less utility costs.

The growth in this sector (smart homes) has occurred as a result of rise in energy costs, lowering of the cost of smart home technologies and government policies providing incentives towards reducing energy consumption.

Smart homes are important for strategic planning and national policy. For a technology such as smart homes to be adopted it is necessary to make sure that you have clear benefits and acceptable levels of risk. In [17] the risks and benefits are measured to determine if smart home technology should be completely adopted into the market. In addition to that they study how to reduce the risks of using smart home technology and increase its benefits.

Smart homes can also assist to reduce the effect of greenhouse gases as well as increasing energy efficiency. There are solutions that make use of information technologies (ICT) [18] to be used in smart homes. These solutions will involve a smart home that uses the full range of ICT based energy management methods. In [18] the consumer perception of using energy management methods are also studied. There they discuss issues of smart metering, variable tariffs, smart appliances and home automation.

Smart homes can be used to assist the elderly and the disabled in a not obstructive way [19]. This can assist the elderly and the disabled to be independent, have good health and prevent them from stressful conditions due to isolation. Smart homes can have sensor and actuators that work in a network environment and collect data. Once the data is collected it can be used to determine the assistance measures required by the elderly. In some instances, the technology can include wearing implants 24 hours a day to assist the elderly and disabled.

\section{Methodology}

This project consists of two main modules which are the hardware module that interfaces with the home peripheral components and the software module that communicates with the microcontroller using Bluetooth. The system uses Bluetooth as the radio communication protocol which acts as the link between the smartphone and the PIC microcontroller.

\section{A. Implementation}

The PIC microcontroller and Bluetooth module are used in the project to control the whole process. The android application on the smart phone is used to send commands to the PIC microcontroller, via wireless Bluetooth. The PIC microcontroller is connected (hardwired) to three relays as 
shown in Fig 2. In this project these relays are connected to different electrical devices. As per the block diagram, a 12 VDC LED bar, 220 VAC Gate motor, 220 VAC light bulb 1 and 220 VAC light bulb 2.

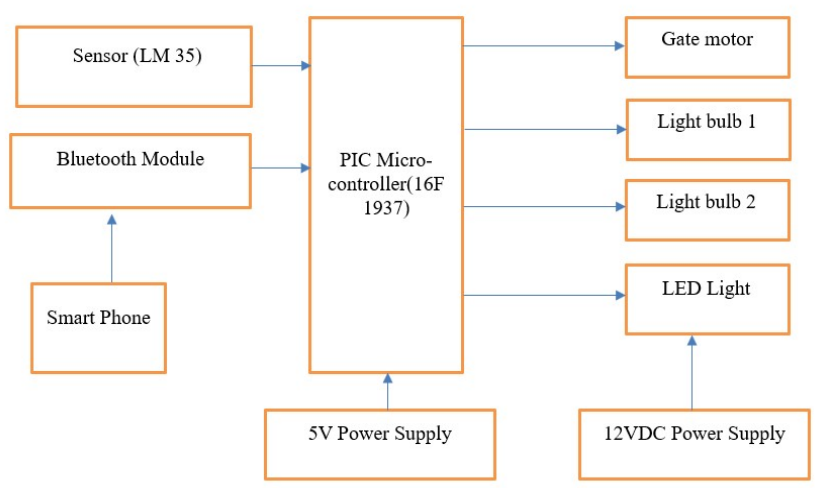

Fig. 2 System block diagram

Fig. 3 shows the schematic design of the project. The circuit was designed using Diptrace software. The schematic design shows the micro-controller, relays, voltage regulators and other peripheral components.

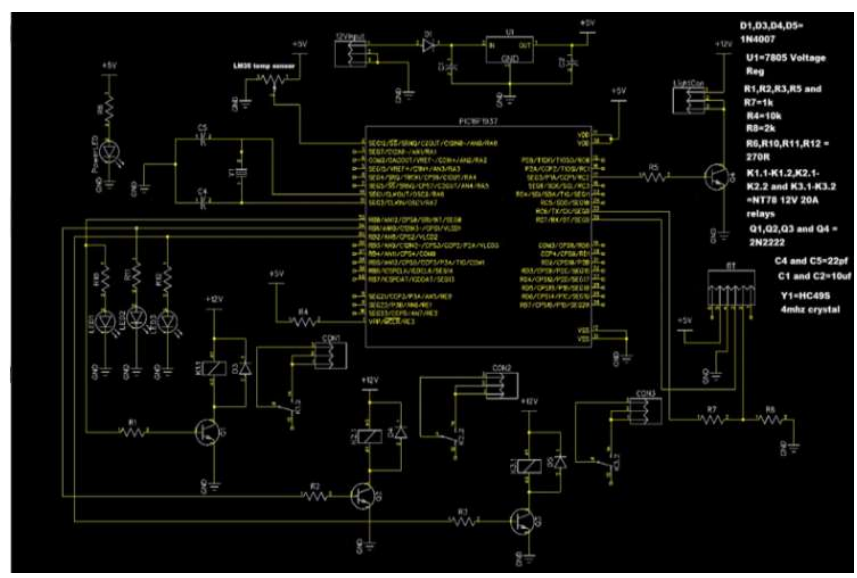

Fig. 3 Schematic diagram

The design of the top side of the printed circuit board is shown in Fig. 4.

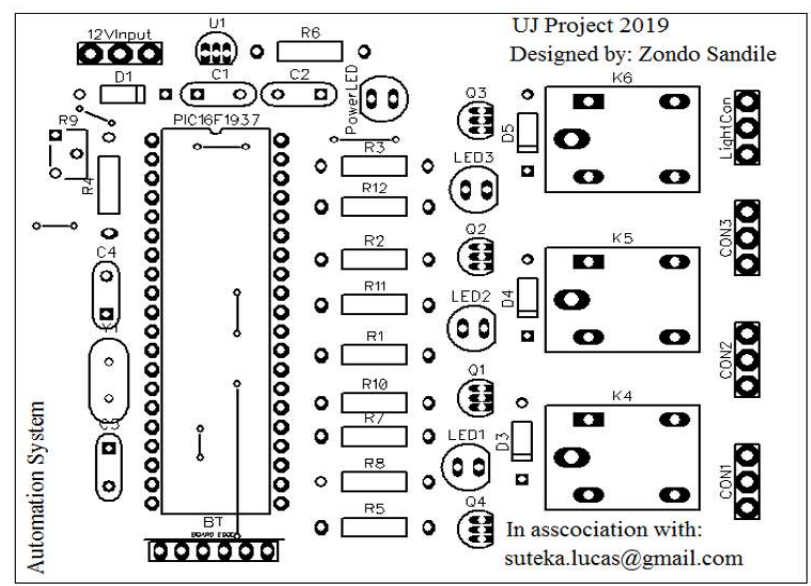

Fig. 4 Printed Circuit board top side
The design of the bottom part of the printed circuit board showing the connections can be seen in Fig. 5 below.

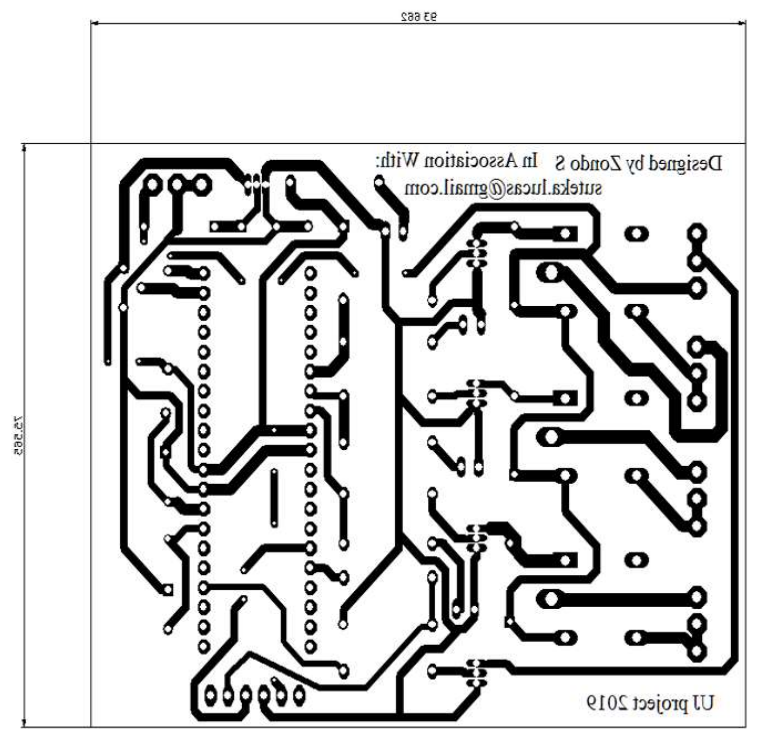

Fig. 5 Printed Circuit board bottom side

The PIC microcontroller is used to control the whole process. Bluetooth is used as a protocol to communicate between the application on the mobile phone and the receiver on the Bluetooth console linked to the PIC. As a result, this controls the home appliances. Icons on the mobile application interface as can be seen in Fig. 6 can be used to send different commands to the receiver on the Bluetooth console. The Bluetooth console communicates with the PIC which will trigger an appropriate relay that can switch "ON" and "OFF" an appropriate device.

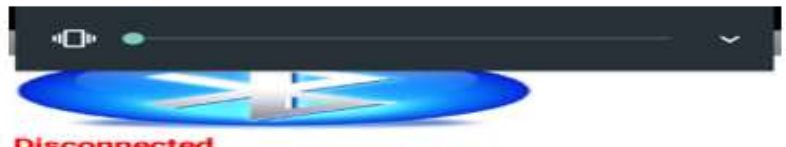

Disconnected
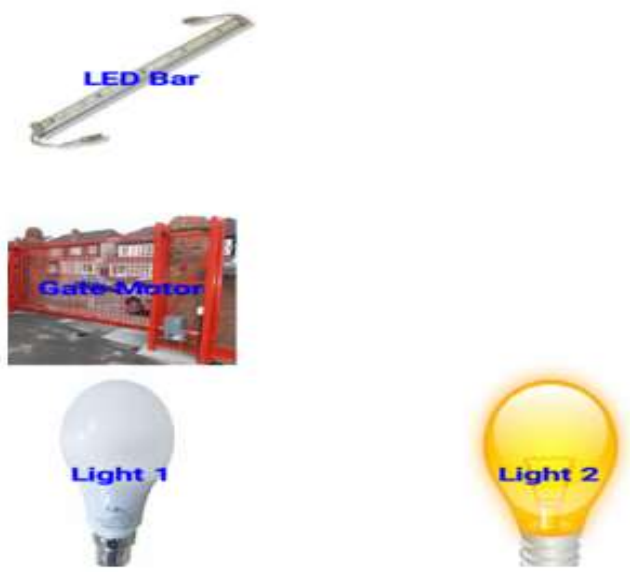

Fig 6 Mobile Phone Application 
Fig. 7 below shows the flow diagram for the design of the code written for the PIC microcontroller, in order to operate the Bluetooth console linked to the PIC and the relays connected to the home devices. The first step in the flow chart start the Bluetooth module, the next step sets the baud rate of communication to $9600 \mathrm{~b} / \mathrm{s}$. Then the voltage is obtained from the temperature sensor and assigned to a variable. Subsequently the Bluetooth console communicates with the smart phone, the value of the temperature is then displayed on the smart phone. Any Setting sent form the smart phone to the Bluetooth console and the microcontroller is then used to determine the duty cycle for the control of the relays connected to the peripheral devices.

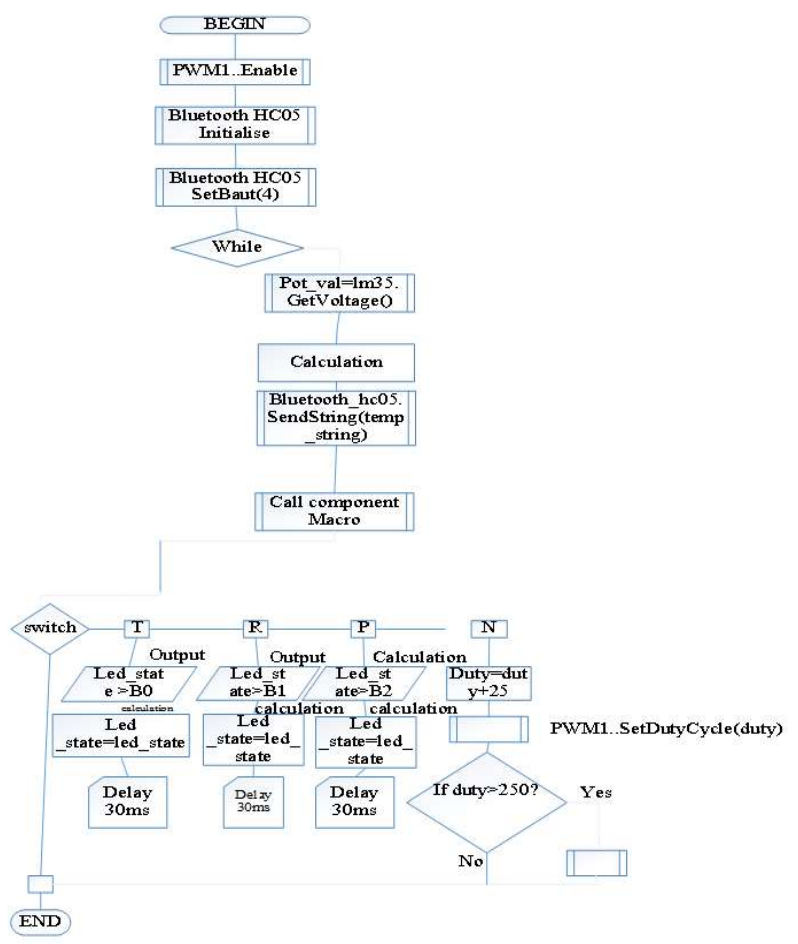

Fig. 7 System Flow Chart

\section{RESULTS}

When the user presses the "LED bar button icon in the application the led bar will switch "ON". The led bar can be switched "OFF", by pressing the icon again. The same process is followed to control the other devices. The process is summarized in table 1 below.

\section{TABLE 1 APPLICATION CONTROL}

\begin{tabular}{|l|l|l|}
\hline Devices & Action perform & Reaction \\
\hline Bluetooth button & $\begin{array}{l}\text { Bluetooth button } \\
\text { Press }\end{array}$ & $\begin{array}{l}\text { Bluetooth devices } \\
\text { will be listed }\end{array}$ \\
\hline Gate motor & $\begin{array}{l}\text { Gate motor button } \\
\text { Press }\end{array}$ & $\begin{array}{l}\text { Gate motor will } \\
\text { switch ON }\end{array}$ \\
\hline
\end{tabular}

\begin{tabular}{|l|l|l|}
\hline Gate motor & $\begin{array}{l}\text { Gate motor button } \\
\text { Again Press }\end{array}$ & $\begin{array}{l}\text { Gate motor will } \\
\text { switch OFF }\end{array}$ \\
\hline Light 1 & Light 1 button Press & $\begin{array}{l}\text { Light 1 will switch } \\
\text { ON }\end{array}$ \\
\hline Light 1 & $\begin{array}{l}\text { Light 1button Again } \\
\text { Press }\end{array}$ & $\begin{array}{l}\text { Light 1 will switch } \\
\text { OFF }\end{array}$ \\
\hline Light 2 & Light 2 button Press & $\begin{array}{l}\text { Light 2 will switch } \\
\text { ON }\end{array}$ \\
\hline Light 2 & $\begin{array}{l}\text { Light 2 button Again } \\
\text { Press }\end{array}$ & $\begin{array}{l}\text { Light 2 will switch } \\
\text { OFF }\end{array}$ \\
\hline Led bar & $\begin{array}{l}\text { Led bar button press } \\
\text { Led bar will switch } \\
\text { ON }\end{array}$ \\
\hline Led bar & $\begin{array}{l}\text { Led bar button again } \\
\text { press }\end{array}$ & $\begin{array}{l}\text { Led bar will switch } \\
\text { OFF }\end{array}$ \\
\hline
\end{tabular}

The complete project prototype can be seen in Fig. 8 below. Fig. 8 shows the microcontroller, lamps, LED and the gate motor for the control of the gate

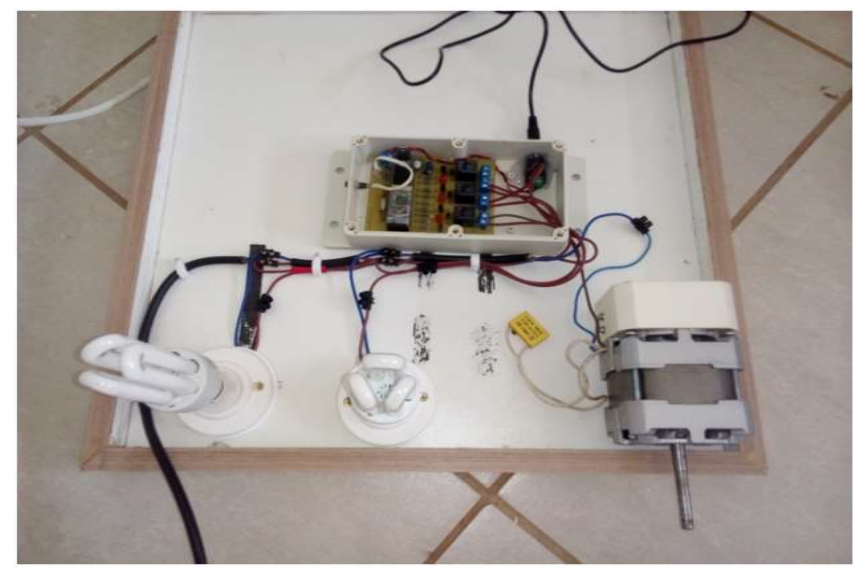

Fig. 8 Smart Home Prototype

\section{CONTRIBUTION TO THE STUDY}

We need to protect our environment from many harmful things in the world, such as pollution, saving energy to preserve the beauty of nature. We need to start saving electricity and other energies consumed. You can save electricity by scheduling the "ON and "OFF" time of all electrical appliances. The utilization of IoT technology can enable you switch of devices that are not in use from a remote location as long as the devices in the smart homes have an IP address linked to them. This can further lead to a reduction in the utilization of energy consumption of homes.

\section{CONCLUSION}

This project reports on the design and implementation of a low cost, flexible and wireless solution to home automation using a PIC microcontroller, an android application and the 
Bluetooth protocol. It gives a brief review on different types of home automation systems. The home automation devices in this paper are controlled by using an android application on a cellphone and the wireless Bluetooth protocol. The devices in the prototype are hard-wired to the PIC microcontroller. These devices can be switched "ON" and "OFF" remotely and conveniently saving the utilization of electricity. The home devices controlled in this project include, lamps, LED, and a gate motor. Researchers around the world are working on integrating technology in home automation to make devices more intelligent and feature rich.

\section{ACKNOWLEDGMENT}

We would like to acknowledge the University of Johannesburg and the University of South Africa for their support in this research work.

\section{REFERENCES}

[1] B. Debnath, R. Dey, S Roy, "Smart Switching System Using Bluetooth Technology", Amity International Conference on Artificial Intelligence (AICAI), 4-6 Feb 2019, Dubai, UAE, [Online]. Available: http://doi.org/10.1109/AICAI.2019.8701298

[2] M. Chan, D. Esteve, C. Escriba, E. Campo, "A review of smart homesPresent state and future challenges", Computer methods and programs in biomedicine, vol. 91, no. 1, pp. 55-81, 2008. [Online]. Available: https://doi.org/10.1016/j.cmpb.2008.02.001

[3] T. Haripriya, J. R. Kanth, "ECA Based Home Automation System", International Journal of Emerging Engineering Research and Technology, vol. 2, no. 4, pp. 340-348, 2014.

[4] V. K. Reddy, P.A. Srinivas, C.A. K. Reddy, M. Mohan, “ Sophisticated Home Automation System Using Bluetooth", International Journal of Pure and Applied Mathematics, vol. 118, no. 20, pp. 719-722, 2018.

[5] R. Teymourzadeh, S. A. Ahmed, K.W. Chan and M. V. Hoong, "Smart GSM Based Home Automation system," IEEE Conference on Systems, Process \& control (ICSPC), 13-15 Dec, 2013, Kuala Lumpur, Malaysia, http://doi.org/10.1109/SPC.2013.6735152

[6] M. Asadullah, and K. Ullah, "Smart home automation system using Bluetooth technology", International Conference on innovation in Electrical Engineering and Computational Technologies (ICIEECT), 5$7^{\text {th }}$ April 2017, Karachi, Pakistan, [Online]. Available: http://doi.org/10.1109/ICIEECT.2017.7916544

[7] R. Marimuthu, A. K. Singh, S. Balamurugan and K. Aroul, " Home Automation using Bluetooth - a review", ARPN Journal of Engineering and Applied Sciences, vol. 11, no. 21, 2016.

[8] R.R. Jogdand and B.N. Choudhari, "DTMF based Home Automation System", IJESC, vol.7, no. 2, 2017.

[9] IEA- International Energy Agency, "Capturing the Multiple Benefits of Energy Efficiency, IEA, Paris, France, 2014.

[10] IEA- International Energy Agency, "Energy prices and taxes", Organization for Economic Cooperation and Development, Paris, France, 2009.

[11] P. Siano, "Demand response and smart grids - A survey", Renewable and Sustainable Energy Reviews, vol. 30, pp. 461-478, 2014, [Online]. Available: https://doi.org/10.1016/j.rser.2013.10.022.

[12] M. Kezunovic, "Smart Fault Location for Smart Grids", IEEE Transactions on Smart Grid, vol. 2, no. 1, March 2011, [Online]. Available: http://doi.org/10.1109/TSG.2011.2118774

[13] F. Li, B. Luo and P. Liu, "Secure Information Aggregation for Smart Grids Using Homomorphic Encryption", First IEEE International Conference on smart Grid Communications, Oct 2010, [Online]. Available: http://doi.org/10.1109/SMARTGRID.2010.5622064

[14] H. Aldowah, S. U. Rehman, S. Ghazal and I. N. Umar, "Internet of Things in Higher Education: A Study on Future Learning", Journal of Physics: Conference Series, vol. 892, The $6^{\text {th }}$ International Conference on Computer Science and Computational Mathematics (ICCSCM 2017), 4$5^{\text {th }}$ May 2017, Langkawi, Malaysia,

[15] A. Zanella, N. Bui, A. Castellani, L. Vangelista and M. Zorzi, "Internet of Things for Smart Cities", IEEE Internet of Things Journal, vol. 1, no. 1,
February,

2014

[Online].

Available:

http://doi.org/10.1109/JIOT.2014.2306328

[16] C. Perera, A. Zaslavsky, P. Christen, and D. Georgakopoulos, "Context Aware Computing for The Internet of Things: A Survey", IEEE Communications Survey and Tutorials, vol. 16, no. 1, pp. 414-454, $3^{\text {rd }}$ May 2013, [Online]. Available: http:doi.org/10.1109/SURV.2013.042313.00197

[17] C. Wilson, T. Hargreaves and R. H. Baldwin, "Benefits and risks of smart home technologies", Energy Policy, vol. 103, pp 72-83, April 2017, [Online]. Available: https://doi.org/10.1016/j.enpol.2016.12.047

[18] A. G. Paetz, E. Dutschke and W. Fichtner, "Smart Homes as a Means to Sustainable Energy Consumption: A Study of Consumers Perceptions", Journal of Consumer Policy, vol. 35, pp. 23 - 41, 2012, [Online]. Available: http://doi.org/10.1007/s10603-011-9177-2

[19] M. Chan, E. Campo, D. Esteve and J. Y. Fourniols, " Smart homes Current features and future perspectives", Maturitas, vol. 64, no. 2, pp. 90 - $97, \quad 20^{\text {th }} \quad$ October 2009, [Online]. Available: https://doi.org/10.1016/j.maturitas.2009.07.014. 